\title{
THERMOGRAPHIC METHOD FOR FATIGUE LIMIT DETERMINATION AT CYCLIC LOADING - MEASUREMENT PROCEDURE OVERVIEW AND VALIDATION
}

\author{
${ }^{1}$ Jiří TESAŘ, ${ }^{1}$ Michal ŠVANTNER, ${ }^{1}$ Jiří SKÁLA, ${ }^{1}$ Petra HONNEROVÁ, ${ }^{2}$ Matyáš NOVÁK \\ ${ }^{1}$ University of West Bohemia, New Technologies - Research Centre, Pilsen, Czech Republic, EU \\ tesar@ntc.zcu.cz,msvantne@ntc.zcu.cz, jskala@ntc.zcu.cz,petrahon@ntc.zcu.cz \\ ${ }^{2}$ Research and Testing Institute Pilsen, Pilsen, Czech Republic, EU, novak@vzuplzen.cz
}

https://doi.org/10.37904/metal.2019.709

\begin{abstract}
The contribution deals with a thermographic method for a determination of fatigue limit of a cyclically loaded sample. Infrared thermography is a method for a noncontact temperature measurement. Quantitative and high accuracy thermographic measurement requires knowledge of optical properties of the measured sample surface. Thermographic paints with high emissivity are often used for these purposes. These paints also should fulfill additional requirements on mechanical loading properties if they are used for cyclic loading tests. Results of several thermographic high-emissivity paints testing are presented. Known fatigue limit testing methods were verified and improved in terms of our research. A novel 2D approach to the thermographic fatigue limit evaluation improves a visualization of the tested part violation. Experiments with different samples, using different loading frequencies and different coefficient of loading force asymmetry were performed to validate the thermographic fatigue testing method. The results of validation tests and a procedure for an automatic online evaluation of fatigue limit thermographic measurement are introduced.
\end{abstract}

Keywords: Cyclic loading, infrared thermography, high emissivity paint, fatigue limit evaluation

\section{INTRODUCTION}

The combination of infrared thermography and cyclic loading testing creates a very interesting and promising solution of fatigue limit evaluation in comparison with standard methods using Wöhler curve.

\subsection{Infrared thermography}

Infrared thermography is an analytic method based on detection of objects radiation in the infrared (IR) range [1]. The temperature of the object can be evaluated by the infrared radiation measurement if the optical properties of the analysed surfaces are known. The intensity of radiation emitted by an object depends not only on the temperature but also on surface optical properties. Such properties are emissivity $\varepsilon$, reflectivity $\rho$ and transmissivity $\tau$ that describe the portion of emitted, reflected and transmitted radiation. Among other properties influencing noncontact temperature measurement belong the ambient temperature (surroundings temperature, so called "reflected temperature") and atmosphere properties (temperature, transmissivity) [2].

The value of emissivity has the crucial importance in the temperature measurement using IR camera. It characterizes the amount of emitted energy as a multiplicative coefficient of Planck's law in the basic equation of infrared thermography. Moreover, it is hidden in the reflectivity of opaque materials with term of $(1-\varepsilon)$. This is very important especially for metallic materials that have in the LWIR region (Long Wavelength Infra Red, 7 $-15 \mu \mathrm{m}$ ) of radiation, in which operates the most of IR cameras, very low values of emissivity, typically less than $0.1[3,4]$. So low emissivity bring big problems to temperature measurement with high accuracy (practically not measurable), because of radiation reflected from the surroundings plays a dominant role in the total amount aiming to the IR camera detector.

There are many options how to improve the emissivity. The most used solution is to apply a high emissive paint to the reflective surface [5]. Among the other ways belong using e.g. carbon coating [6] or to improve the 
surface with laser [7] or with increasing roughness [4]. For the usability in cyclic loading it is necessary to fulfill the complex set of parameters, not only high emissivity (i.e. of course low transmissivity of added layer, too), but also mechanical properties like stiffness (no cracks after loading), adhesion to material and no influence to the experiment. The research of properties of proper paint is shown in paragraph 2.

\subsection{Thermographic methods for fatigue limit evaluation}

There were revealed many thermographic methods in the past. The origins come from Italy where A. L. Geracy at al. showed that the temperature of specimens, subjected to cyclic loads, increases at a rate determined by the applied load and number of cycles [8]. There are two basic approaches to the problematic of fatigue limit determination - the first group of published articles works with temperatures measured during cyclic loading and the second group works with the energy balance.

The main idea of using temperatures for evaluation is that with increasing stepped loading changes the temperature trend as the initial elastic deformation changes to following plastic deformation. The Method 1 [9] consists of making various constant amplitude fatigue tests with stresses higher than fatigue limit which value is determined as the intersection of linear approximation line of temperatures with the load axis on the graph. The Method 2 [10] consists of a stepped loading procedure which starts from loading levels lower than expected value of fatigue limit that is obtained as an intersection of a linear approximation of the first and second stage of the temperature increase. Both of mentioned methods and their modifications were used for testing of many samples as mentioned in introduction part of pervious work [11,12].

The main idea of the energy balance is the calculation of the energy transferred to the sample material using its material properties and temperature. The internal energy increase can be taken into account as the area under $T=f(N)$ curve where $N$ is number of loading cycles [13]. A theoretical analysis of energy balance was introduced by Luong [14]. A combination of acoustic emission method and thermographic method was used in [15]. The calculation of released energy, that is constant for different loads, as an product of temperature difference and number of cycles to failure is used in [16] for fatigue limit evaluation.

\section{IMPROVEMENT OF SAMPLE SURFACE}

As mentioned above, the knowledge of surface emissivity and its high value contribute to the practicability and high accuracy of temperature measurement using IR thermography. Used high emissivity paints have to fulfill additional requirements on mechanical loading properties. Results of optical properties measurement and thermo-mechanical properties testing are presented below.

\subsection{Optical properties of high emissivity paints}

The requirement to the paint is the highest emissivity and the lowest transmissivity and reflectivity in the spectral range of used IR cameras. These optical properties (transmissivity $\tau$ and reflectivity $\rho$ ) were measured using FTIR spectrometer and the emissivity $\varepsilon$ is obtained with the same procedure as in [17] as result of energy conservation relation: $\varepsilon=1-\rho-\tau$.

As an example of almost 30 tested paints spectral dependence of one of the most suitable paint from the optical point of view is shown. The Figure 1 shows the spectral dependence of emissivity, transmissivity and reflectivity of the tested paint. For the thermographic

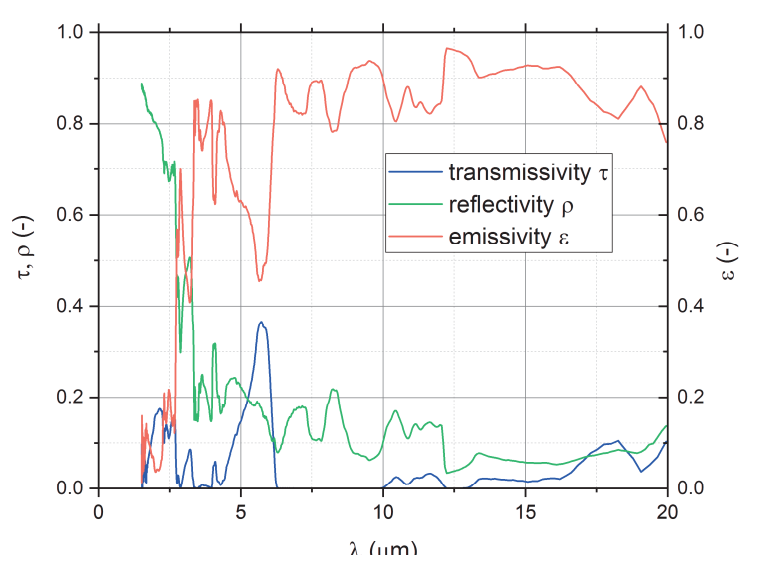

Figure 1 Spectral dependence of optical properties of the tested paint (measured reflectivity $\rho(\lambda)$ and transmissivity $\tau(\lambda)$ and calculated emissivity $\varepsilon(\lambda)$ ) 
measurements the value of emissivity is averaged for the wavelength region of the camera detector $(7.5-13$ $\mu \mathrm{m})$.

\subsection{Thermal and mechanical testing of high emissivity paints}

Optical properties of paints are important for using of thermographic measurement of cyclic loaded samples but thermal and mechanical testing is needed. The high emissivity paint has to be resistant to the temperature that can occur during the cyclic test - see the results of thermal loading at Figure 2 a). The paint has to be able to resist to the deformation of the sample during the cyclic loading - tension vs. compression behavior see Figure 2 b).

a)

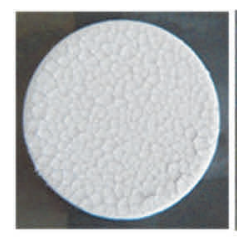

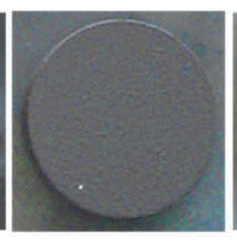

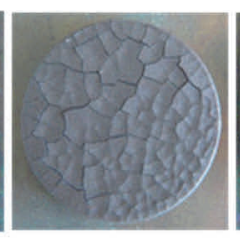

b)

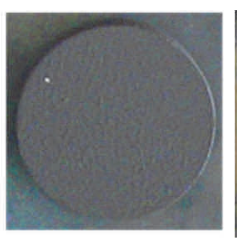

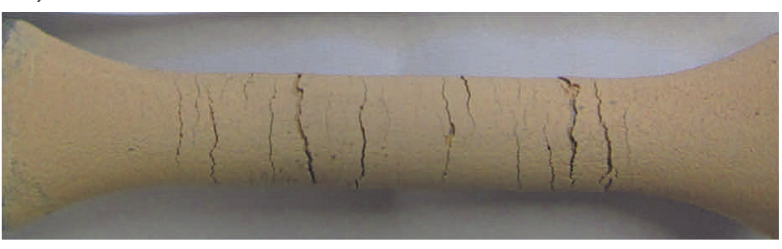

Figure 2 a) An example of some paints surface after heating to high temperature, b) an example of coating after cyclic loading - the ruptures of tested coating are clearly seen

The most suitable paint from all tested paints has high average value of emissivity $\varepsilon=0.93$, very low transmissivity in the LWIR region $(\tau<0.05)$ and is mechanically and thermally stable.

\section{FATIGUE LIMIT MEASUREMENT AND EVALUATION}

Two samples of $10 \mathrm{~mm}$ diameter from 15Ch2NMFA steel were measured with frequency of loading $10 \mathrm{~Hz}$ and sinusoidal asymmetry R0.1 - in detail described in previous presented work $[11,12]$ and ten samples of $3 \mathrm{~mm}$ diameter from AK1.9 (X12Cr13, 17 021) steel with frequency of sinusoidal loading $122 \mathrm{~Hz}-6$ of them with asymmetry R0.1; 2 samples with asymmetry R0.5 and 2 samples with asymmetry R1.

\subsection{Principle of fatigue limit measurement}

The used method is based on stair-case increasing of loading force with equidistant step during cycling testing with constant time duration. Surface temperature of tested sample is measured using IR camera during this process. The maximal value of temperature from analysed area is determined for each step and the graph of temperature dependence on applied load is constructed. Data from this graph can be divided into two groups - group A (temperature values corresponding to loads lower than expected value of fatigue limit) and group B (temperature values corresponding to load higher than expected fatigue limit) and these data sets are linearly interpolated. The intersection of lines can be identified as a fatigue limit value if the condition that the fatigue limit value is higher than the highest load of region $A$ and at the same time lower that the lowest load value of region $B$ is fulfilled (the intersection of lines lies between regions $A$ and $B$ ).

\subsection{Fatigue limit evaluation}

The fatigue limit evaluation procedure mentioned above can be done in several ways. The first one is to change the measured values distribution to groups $A$ and $B$ manually after the measurement (offline) and to try if the necessary condition is fulfilled until all possibilities are checked - Figure 3 a). The second possibility is to make the distribution automatically online during the measurement as is implemented in software module developed in our laboratory - Figure $3 \mathbf{b}$ ). 
a)

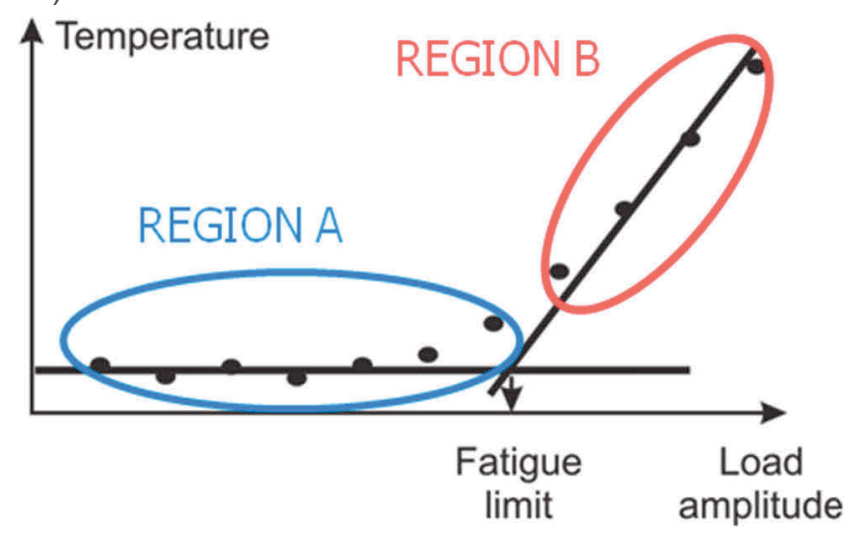

b)

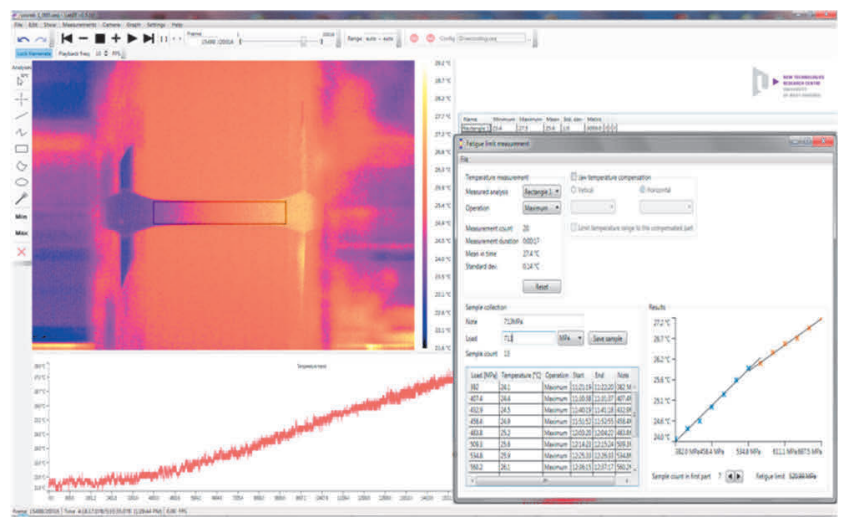

Figure 3 a) Procedure of offline fatigue limit evaluation, b) automatic online evaluation in the thermographic software

The third option is to work with all pixels of the tested sample and to use the same procedure as for the two first cases (online/offline evaluation) for all points separately.

\section{RESUTLS}

Averaged results of online/offline evaluation (1st and 2nd option of evaluation) are summarized in Table 1.

Table 1 Results of fatigue limit evaluation using infrared thermography methods

\begin{tabular}{|c|c|c|c|}
\hline Sample & Loading frequency $\mathbf{( H z})$ & Asymmetry & Fatigue limit (MPa) \\
\hline 15Ch2NMFA & 10 & $\mathrm{R} 0.1$ & 525 \\
\hline \multirow{3}{*}{ AK1.9 } & \multirow{3}{*}{122} & $\mathrm{R} 0.1$ & 537 \\
\cline { 2 - 4 } & & $\mathrm{R} 0.5$ & 569 \\
\cline { 2 - 4 } & & $\mathrm{R} 1$ & 211 \\
\hline
\end{tabular}

The result fatigue limit value of standard method using Wöhler curve is $464 \mathrm{MPa}$ for 15Ch2NMFA testing with asymmetry 0.1 and $578 \mathrm{MPa}$ for AK1.9 testing with asymmetry of 0.1 and frequency of $122 \mathrm{~Hz}$. The standard method testing wasn't realized for the other asymmetries due to high demands for time and number of samples. The results of thermographic evaluation are in good agreement with results of standard method.

a)

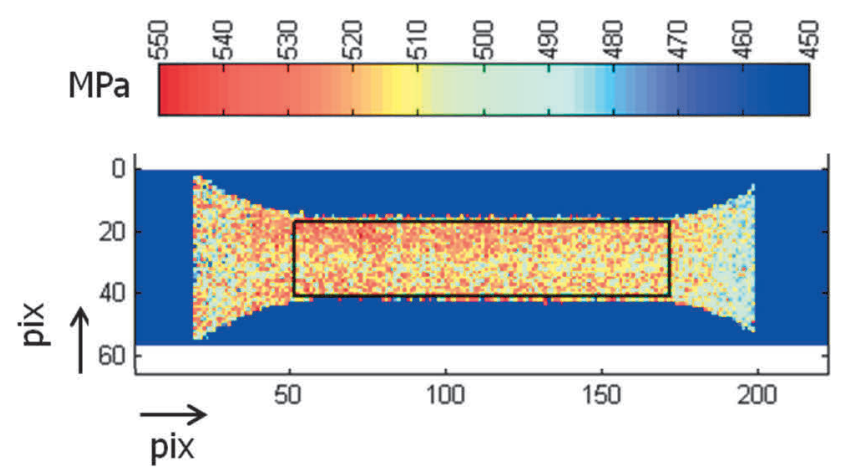

b)

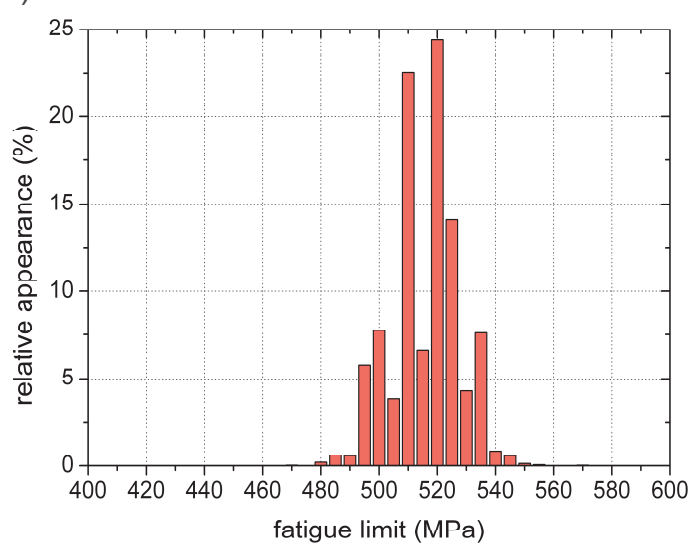

Figure 4 a) Example of 2D map of evaluated values of the sample from 15Ch2NMFA, b) histogram of resulting values in the central part of the sample 
A 2D map of the sample corresponding to the third way of evaluation was created for the second sample of 15Ch2NMFA steel - see Figure 4 a). The resulting figure proves the high homogeneity of evaluated values that can be presented in the form of histogram of the selected part of the sample - see Figure $\mathbf{4} \mathbf{b}$ ).

The 2D map can be created for the samples made of AK1.9 (diameter of $3 \mathrm{~mm}$ ) too. But there are only 15 pixels across the thickness of the sample because the spatial resolution of the used IR camera limit $5 \mathrm{pix} / \mathrm{mm}$ is reached for the camera to sample distance of $0.5 \mathrm{~m}$.

\section{CONCLUSION}

In the contribution the problematic of surface improving to reach high and homogeneous emissivity is introduced that is necessary for high accuracy of thermographic measurement. Procedure of emissivity measurement from other optical properties (reflectivity and transmissivity) is mentioned and the need of thermal and mechanical stability of the paint is shown. Fatigue limit measurement and evaluation methods are briefly described and results of measurement of different samples and parameters are summarized in a table. An example of $2 \mathrm{D}$ evaluation is introduced.

\section{ACKNOWLEDGEMENTS}

The work has been supported by the Technology Agency of the Czech Republic within the project no. TE01020068 and by the Ministry of Education, Youth and Sports of the Czech Republic within the OP RDI program, CENTEM project, no. CZ.1.05/2.1.00/03.0088, co-funded by the ERDF; and National Sustainability Programme I., CENTEM PLUS project, no. LO1402.

\section{REFERENCES}

[1] GAUSSORGUES, G. and CHOMET, S. Infrared Thermography. 1st ed. Amsterodam: Springer Netherlands, 2012. p. 123.

[2] MALDAGUE, X. P. Nondestructive evaluation of materials by infrared thermography. 1st ed.London: SpringerVerlag London Limited, 1996. p. 132.

[3] OPTRIS, Non-contact temperature measurement on metal surfaces via infrared, p. 4.

[4] JO, H. J., KING, J.L., BLOMSTRAND, K and SRIDHARAN, K. Spectral emissivity of oxidized and roughened metal surfaces, International Journal of Heat and Mass Transfer. 2017. vol. 115, no. 12, pp. 1065-1071.

[5] GRUM J. and KEK, T. The influence of different conditions of laser-beam interaction in laser surface hardening of steels. Thin Solid Films. 2004. vol. 453-454, pp. 94-99.

[6] MORADI, M., KARAMI MOGHADAM, M. and KAZAZI, M. Improved laser surface hardening of AISI 4130 low alloy steel with electrophoretically deposited carbon coating. Optik. 2019. vol. 178, no. 2, pp. 614-622.

[7] TESAR, J., VACIKOVA, P., SOUKUP, O and HOUDKOVA, S. Infrared camera analysis of laser hardening. Advances in Optical Technologies. 2012. vol. 6, pp. 24-37.

[8] GERACI, A. L. , LA ROSA, G. and RISITANO, A. On the new methodology for the determination of the fatigue limit of materials using thermal infrared techniques. in Proceedings of the VDI-IMEKO/GESA Symposium, Düsseldorf: ABC, 1992, pp. 183-190.

[9] MORABITO, A. E., DATTOMA, A. E.. and GALIETTI, G. Energy analysis of fatigue damage by thermographic technique. Thermosense XXIV, International Society for Optical Engineering. 2002, vol. 4710, pp. 456-463.

[10] ROSA, G. LA and RISITANO, A. Thermographic methodology for rapid determination of the fatigue limit of materials and mechanical components. International Journal of Fatigue. 2000. vol. 22, no. 1, pp. 65-73.

[11] TESAŘ, J., SKÁLA, J., ŠVANTNER, M. and NOVÁK, M. Online evaluation of material fatigue limit using infrared thermography. in METAL 2017: 26th International Conference on Metallurgy and Materials. Ostrava, TANGER. 2017. pp. 377-382. 
[12] TESAŘ, J., ŠVANTNER, M., SKÁLA, J. and NOVÁK, M. Fatigue Limit Evaluation Using Thermographic Measurementduring Cyclic Loading - 1D and 2D method. In Metal 2018: 27th Int. Conf. on Metallurgy and Materials. Ostrava: TANGER, 2018, pp. 603-608.

[13] LIPSKI, A. Accelerated determination of the fatigue limit and the s-n curve by means of the thermographic method for x5crni18-10 steel. Acta Mechanica et Automatica. 2016. vol. 10, no. 1, pp. 22-27.

[14] LUONG, M.P. Infrared thermographic scanning of fatigue in metals. Nuclear Engineering and Design. 1995. vol. 158, no. 2-3, pp. 363-376.

[15] LA ROSA, G., CLIENTI, C. and LO SAVIO, F. Fatigue analysis by acoustic emission and thermographic techniques. Procedia Engineering. 2014. vol. 74, pp. 261-268.

[16] FARGIONE, G., GERACI, A, LA ROSA, G. and RISITANO, A. Rapid determination of the fatigue curve by the thermographic method. International Journal of Fatigue. 2002. vol. 24, no. 1, pp. 11-19.

[17] HONNEROVÁ, P., MARTAN, J., VESELÝ, Z. and HONNER, M. Method for emissivity measurement of semitransparent coatings at ambient temperature. Scientific Reports. 2017. vol. 7, pp. 1-8. 